\title{
PODER POLÍTICO, INSTITUIÇÕES E PLURALISMO JURÍDICO NO MEDIEVO PORTUGUÊS
}

\section{Davi de Paiva Costa Tangerino ${ }^{1}$ \\ Henrique Olive ${ }^{2}$}

\section{Resumo}

O presente trabalho tem como objetivo debater conflitos institucionais em meio a uma experiência histórica de pluralismo jurídico, buscando apresentar um exemplo de disputa por poder político institucional cujo instrumento principal é a expansão jurisdicional. Para isto, aprofunda-se o estudo da clássica historiografia portuguesa sob o crivo dos preceitos metodológicos da historiografia contemporânea, somado a um escrutínio da bibliografia moderna, que nas últimas décadas retomou o debate quanto às relações entre instituições locais e centrais no medievo português, bem como quanto ao exercício de suas jurisdições. Com base nos elementos apresentados, é possível concluir pela importância dos exemplos históricos nos debates sobre instituições políticas e suas interrelações, bem como pelo papel fundamental do Direito enquanto instrumento de expansão e legitimação de poder desde a formação de nossa cultura política.

Palavras-chave: conflitos institucionais; pluralismo jurídico; poder político central e local; história política; história de Portugal.

\section{INTRODUÇÃO}

Este trabalho se propõe a debater seu objeto por meio do estudo das relações políticas entre instituições

\footnotetext{
${ }^{1}$ Pós-doutor em Direito pelo Max Planck Institut (Alemanha) (2010); Doutor (2009) e Mestre (2005) em Direito Penal pela USP, com estágio doutoral na Humboldt Universität (Alemanha); Professor de Direito Penal da UERJ/RJ e da Escola de Direito da FGV/SP. E-mail: professordavitangerino@gmail.com

${ }^{2}$ Mestre em Direito penal Universidade do Estado do Rio de Janeiro (UERJ); Pós Graduado em Processo Pena e Garantias Fundamentais pela Academia Brasileira de Direito Constitucional.E-mail: henriqueoolive@gmail.com
} 
portuguesas do período medieval a partir da figura do Rei. Sua importância é notória para a história e a ciência política dos países lusófonos, incluso o Brasil (MARQUES, 1993; MENDONÇA, 2010), em que pese a habitual obliteração da história como instrumento de crítica, em favor de seu uso como instrumento legitimador (HESPANHA, 2012).

Ou seja, a problematização que a história das instituições oferece à compreensão das relações sociais e ao próprio papel do direito em sociedade permanece restrita a um pequeno âmbito de "jus-historiadores". Isto porque, mesmo na área jurídica, a tradicional abordagem concebe a jus-historiografia como história das fontes ou, no máximo, história da dogmática (HESPANHA, 1982). Ou seja, o estudo crítico das instituições, de sua realidade, significativamente apartado de previsões normativas, esteve esquecido.

No que toca especificamente a jus-historiografia portuguesa, apenas no último quartel do século XX floresceram estudos críticos acerca do tema, em especial na Faculdade de Direito da Universidade Nova de Lisboa, na Faculdade de Letras do Porto e na Faculdade de Letras de Coimbra. Destacam-se os pesquisadores Armando Luís de Carvalho Homem e António Manuel Hespanha, que, ao revisitar o debate, foram além da subserviência da historiografia portuguesa à obra de Henrique da Gama Barros, Historia da Administração Pública em Portugal nos séculos XII a XV(MORENO, 1991).

Diversos outros pesquisadores deram similares passos, como Armindo de Sousa, José Marques, José Mattoso, Maria Helena da Cruz Coelho, Humberto Carlos Baquero Moreno, Manuela Mendonça, António Matos Reis, Francisco Ribeiro da Silva e Luís Miguel Duarte.

O referido descaso com o passado português é ainda mais perceptível na produção brasileira. Em um país recém-emancipado, que reagiu contra a antiga posição de submissão colonial, parece ainda mais distante a ideia de buscar nas origens do direito público do colonizador alguma resposta, ainda que os construtores do império fossem essencialmente de formação portuguesa.

Esta interferência de natureza política na metodologia da historiografia é bem observada por Hespanha como promotora de uma "história erudita e passadista", em que se sobressaem a exultação da nação e projetos ideológicos (1982). É possível que seja, no mínimo, uma explicação concorrente para o afastamento entre jushistoriografia brasileira e as origens portuguesas. Pode-se, entretanto, citar alguns destacados jus-historiadores brasileiros que já se debruçaram, direta ou indiretamente, sobre o tema, como Arno Wehling (IHGB), Arno Dal Ri Junior, Antônio Carlos Wolkmer e Airton Sealaender (UFSC), Ana Lucia Sabadell (UFRJ).

Neste contexto, este trabalho pretende trabalhar com o período que envolve os séculos XI, XII, XIII e $\mathrm{XIV}$, analisando, sinteticamente, o tema de instituições medievais portuguesas sob a ótica de relações políticas e pluralismo jurídico.

Têm-se como fontes principais os referidos trabalhos de revisitação apresentados em comunicações e, 
posteriormente, publicados em diversas revistas especializadas de Portugal; e também, os clássicos historiadores portugueses, como Alexandre Herculano, Oliveira Martins e Henrique da Gama Barros.

\section{BREVE INTRODUÇÃO METODOLÓGICA}

Quanto à metodologia, trabalha-se considerando a impossibilidade de estudar as instituições do Portugal medieval sem perpassar por todo um bojo de condições, circunstâncias e consequências muito além de "fontes" e "dogmática”. Com intuito de facilitar a compreensão do que se afirma, pode-se aplicar esta técnica historiográfica à observação de uma obra de arte, por exemplo, uma pintura: Le Sacre de Napoleon (A Coroação de Napoleão) do pontífice da pintura neoclássica, Jacques-Louis David (1748-1825).

Nesta obra, o revolucionário David retrata a coroação imperial de Napoleão Bonaparte e sua esposa, Josefina de Beauharnais, a 02 de dezembro de 1804, na Catedral de Notre-Dame. Se observarmos apenas o fragmento central da obra — em paralelo às "fontes" - veremos uma bela festa para o coroado Napoleón ler. Entretanto, ao observar o conjunto, notam-se elementos inicialmente despercebidos. Dentre tais, tem-se a peculiar situação do então coadjuvante Papa Pio VII, relegado a segundo plano, em detrimento da tradicional cerimônia Bourbon. Ainda, está o Papa cercado por eclesiásticos de confiança de Napoleão, controlado; e em posição topográfica inferior a Maria Bonaparte, mãe de Napoleão, inserida no centro e à tribuna, em que pese não ter comparecido à cerimônia.

Em suma, a obra é um retrato político do período histórico francês forjado pelo então mais poderoso homem da França. É incapaz de demonstrar a realidade francesa, mas apenas de reforçar a criação de um mito.

Este estudo também sofre com este problema. Afinal, o que se alcança é a elaboração de um quadro -escrito, em vez de óleo sobre tela -- carregado de impressões e percepções dos autores, que sofrem com as amarras de um passado que não se deixa ser plenamente alcançável (BLOCH, 1992), bem como estão necessariamente influenciados pelo pensamento de seu tempo e experiências pessoais.

Este quadro é pintado com fragmentos, sendo impossível ao trabalho jus-historiográfico recriar a totalidade dos fatos; o estudo (escrita) histórico não simplesmente descreve, mas sim, cria, preenche, desenvolve (HESPANHA, 2005). Pode-se dizer que sequer os indivíduos de um período histórico seriam capazes de senti-lo em sua totalidade, tamanha a complexidade dos homens e de suas relações sociais.

Ademais, trata-se de um período longo, que inviabiliza a pormenorização de diversos elementos, mas permite a compreensão do desenvolvimento e transformações de instituições políticas. Portanto, é imperioso trata-las inseridas em um encadeamento de fatos sociais, políticos, jurídicos e econômicos.

Porém não basta esta abordagem, sendo necessário afastar-se de dois problemas metodológicos 
recorrente na historiografia: o continuísmo e o evolucionismo.

O primeiro é o processo que compila conteúdos de textos legais, que se desenvolveriam gradativa e sequenciadamente (Kontinuitätsdenken); ignora, portanto, nuances relacionadas à mentalidade dos homens a quem o direito se dirige e a forma com que estes se relacionam com o direito. Também esquece a fracionariedade das sociedades, que dificilmente mantêm uma ordem social estanque, passando por significativas transformações em suas bases e expressões (SABADELL, 2003).

Já o evolucionismo traz como regra natural o desenvolvimento progressivo e "civilizatório" da sociedade, de modo que os povos, com o passar do tempo, mais civilizados e mais juridicamente organizados, estariam sempre o mais próximo possível da perfeição (SABADELL, 2003), construção de excelência à legitimação do status quo.

Ou seja, as transformações das instituições não são necessariamente progressos, resultados de um processo de aperfeiçoamento e adequações civilizatórias; mas, sim, são vetores do complexo social analisado, em que se inserem intrinsecamente questões econômicas, culturais e políticas.

\section{APONTAMENTOS INICIAIS SOBRE FEUDALISMO E IDADE MÉDIA}

O imaginário comum reconhece no feudalismo características atribuídas por uma revolução que se opõe radicalmente ao passado como forma de autoafirmação, não é à toa a utilização do termo "idade média", que já denota um tom pejorativo (FRANCO JÚNIOR, 2001), e ainda mais, do termo "idade das trevas", que se refere a uma existência primitiva; a um período de reclusão e inexistência econômica. Tal revolução se deu em diversos âmbitos, mas certamente é dos tinteiros das "ciências renascentistas" e dos ideais liberais do século XVIII que advém referida imagem do período, tanto que o substantivo feudalismo remonta, no mínimo, ao século XVII (HESPANHA, 2006).

Montesquieu dirige dois de seus livros de Do Espírito das Leis para tratar do que chama de "teoria das leis feudais entre os Francos, em sua relação com o estabelecimento da monarquia" e "teoria das leis feudais entre os Francos, na relação que têm com as revoluções de sua monarquia"; e afirma que as "leis feudais" são um fato que possivelmente nunca mais se repetiria (1945). Pouco tempo depois a Assembléia Nacional Constituinte reforçou a construção de uma imagem do feudalismo por meio de seu decreto de 11 de agosto (de 1789), que visava à extinção dos "direitos feudais", então já superados (MANFRED, 1986); porém, como questionou Bloch em referência ao ideário revolucionário, como ousar duvidar de uma realidade feudal cuja derrocada custara tantos sacrifícios (1992)?

Ainda que o senso comum acerca da idade média carregue consigo elementos próximos daqueles 
encontrados por trabalhos historiográficos metodologicamente desenvolvidos, resta necessário fazer uma sintética análise dos principais elementos presentes na sociedade feudal, de modo que fique mais bem situado o contexto das instituições objeto de estudo.

Preliminarmente, é imprescindível destacar que nenhum sistema de instituições e relações sociais — seja político, religioso etc. — pode ser visto como total na Europa medieval, sequer podendo-se verificar situações rigidamente similares em territórios vizinhos. Assim, o "fenômeno do feudalismo" na idade média deve ser visto como um grupo razoável de elementos que estão presentes, em maior ou menor escala, em uma tão significativa incidência ao ponto de se poder lidar virtualmente com um fenômeno total em âmbito espacial europeu.

É comum que os estudos históricos tomem como um divisor de águas, como forma de facilitar a compreensão do estudo, o que se chama de Revolução Feudal, devendo-se ter em conta que é apenas símbolo de todo um processo gradual de transformação social. O período que antecede a referida revolução feudal é o que Bloch chama de "primeira idade feudal" (1992), que pode ser traçada, apenas a título didático, desde o estabelecimento dos povos germanos sobre as ruínas do Império Romano até o século X, que antecede o período objeto deste estudo.

Como característica principal, tem-se no feudalismo deste período a existência de "concessões territoriais pelo senhor, acompanhadas da delegação de poderes soberanos, em troca de uma promessa, por parte do vassalo, de fidelidade e de prestação de serviços pessoais nobres" (HESPANHA, 1982, p. 84); e os elos não são apenas jurídico-políticos, mas também mitológicos.

Ainda, é fortemente marcado por uma insegurança a que toda a Europa é submetida, seja pelo Norte (Escandinavos), Leste (Húngaros), ou Sul (Árabes ou Arabizados). Estes últimos, certamente os mais bemsucedidos quanto à dominação política e territorial; viriam a ser expulsos da península ibérica apenas no fim do século XV.

Entretanto, o longo período que os Árabes permaneceram na península ibérica se deve à forma com que se relacionavam com os povos conquistados, representando, em vez de ruptura e extinção, alguma tolerância e manutenção; pois, a construção do direito com base na religião acarretava um sistema jurídico personalista, do qual eram integrantes apenas os crentes. O exercício da religião definia a sujeição ao direito (COSTA, 2010).

Assim, os cristãos e judeus eram tolerados. Os moçárabes -- cristãos em territórios de dominação árabe -- puderam manter seus costumes, instituições e, portanto, certa autonomia-administrativa; entretanto, eram protegidos do Islão (ahlal-dhimma), e estavam submetidos ao pagamento de um imposto de capitação (jizya).

De qualquer forma, a insegurança do período medieval é indiscutível, justificando a importância que se deu aos indivíduos militares e aos clérigos no período, afinal, não é apenas material, é também moral; é uma insegurança quanto à salvação da alma condicionada aos sobressaltos da vida terrena (LE GOFF, 1999). 
Entretanto, este contexto promove o mito da inexistência de circulação e da economia exclusivamente de subsistência, que impede que se percebam importantes características do período.

A alta idade média é marcada, sim, por baixa densidade demográfica europeia (BLOCH, 1992); concentração de habitantes em determinados locais; e pequena circulação de pessoas e bens (FRANCO JÚNIOR, 2001). Entretanto, o grau destas circulações vai além do que a historiografia tradicional estimava, apesar dos grandes perigos a que estavam submetidos os aventureiros; ocorriam não apenas em âmbito europeu, alcançando o oriente próximo (BLOCH, 1992), ainda que todas estas não se dessem por grandes rotas -demandantes de manutenção pública, o que restou impossível desde o declínio do Império Carolíngio -- mas sim por meio de inúmeras pequenas rotas. Quanto à circulação de bens, vê-se que seu principal meio é o pagamento de tributos e a contraprestação a serviços, em função da carência monetária (BLOCH, 1992).

Quanto ao exercício de poder na primeira idade feudal, vê-se que predominava a força local, haja vista a dificuldade e insegurança nas locomoções (BLOCH, 1992), em que pese a tentativa unificadora do Sacro Império Romano-Germânico. Não à toa aquele que quisesse estabelecer poder sobre uma extensão territorial teria uma árdua tarefa (MICHELET, 1992), afinal, "teria sido impossível governar um país do interior dum palácio: para dominar um país, não há outro meio senão percorrê-lo sem descanso, em todos os sentidos. Os reis da primeira idade feudal mataram-se, literalmente, de tanto viajarem" (BLOCH, 1992:83).

Enfim, agora mais diretamente sobre o objeto deste estudo, a partir do século XI será possível verificar o que pode ser chamado de segunda fase do feudalismo. Bloch denomina-a "segunda idade do período feudal" (1992, p. 90); Henri Pirenne, "época de restauração" (1973, p. 65); Le Goff, a "renascença européia" (1997, p. 111).

Neste período são notórias as modificações, ainda que não sejam superações propriamente ditas das condições do período anterior; isto porque se operou apenas uma "atenuação das condições anteriores" (BLOCH, 1992, p. 92), promovida, principalmente, por um incremento populacional europeu. O aumento da densidade demográfica resultou na maior aproximação entre grupos de indivíduos e na ocupação de espaços, permitindo a proliferação de mercadores e o surgimento de um equilibrado mercado. Com isto, promoveu-se o monetarismo e as relações assalariadas, diminuindo sobremaneira a troca de bens por serviços (BLOCH, 1992).

Porém, é imprescindível compreender como as pessoas se encaixavam neste contexto; como se organizavam e inter-relacionavam. $\mathrm{O}$ imaginário comum separa muito nitidamente a nobreza, o clero e o povo, o que pode decorrer do famoso quadro político sob a monarquia, dita absolutista, em França (séc. XVII-XVIII). Ocorre que este é um quadro demasiado localizado; o reconhecimento do povo como uma classe foi um processo complexo em toda a Europa. Porém, não custa ressalvar que este "povo" que viria a obter algum poder político tinha pouco de povo na acepção contemporânea: "pobre e humilde" — como exposto adiante na análise 
das cortes portuguesas.

A doutrina gelasiana teve o papel de separar os papéis daqueles que mereciam algum valor por sua função: defensores militares cuidam da paz territorial e do corpo físico da sociedade; já os defensores eclesiásticos, da paz espiritual e da boa ventura da alma. Ou seja, bellatores e oratores com funções sociais bem definidas (DUBY, 1994).

Naturalmente, a doutrina eclesiástica, que promove uma rígida hierarquia, não colocava os laicos à frente de seus. Santo Agostinho já afirmara que primeiro Cristo, depois os homens de Cristo e por fim os que em Cristo acreditam. Em síntese, toda a ordem social pauta-se na religião; tem por base, em última instância, as doutrinas de São Paulo e São Pedro: a primeira traz que todo poder vem de Deus (LE GOFF, 2007); enquanto a segunda defende que "todos sois súbditos dos reis ou dos duques que os reis governam" (DUBY, 1994, p. 85).

Eis a origem de uma das grandes questões do período medieval: o monarca, o mais elevado dentre os nobres, é um delegado na terra, mas sua relação com Deus seria direta ou intermediada pelos "homens de fé"? A relação de poder entre monarcas e eclesiásticos — bispos e papas — amoldava-se de acordo com as condições políticas, ou seja, o alcance da autoridade era "negociado" entre as "partes" interessadas (SANTOS, 2009, p. 98).

É justamente deste conflito entre clérigos e nobres que exsurge o povo como ente político. É ideologicamente "emancipado" dos nobres nesta relação binária, de modo a torná-la trinária, triangular. "A triplicidade nasce de uma conjunção das dissemelhanças instauradas conjuntamente pela ordo — há os padres e os outros - e pela natura: há os nobres e os servos" (DUBY, 1994, p. 137): os primeiros, com armas; os segundos, com pás. Isto se dá, pois, o pensamento eclesiástico, em especial com Adalbéron de Laon, pauta-se em um determinismo que estanca alterações sociais; para esta doutrina, a sujeição é hereditária e dela decorre a obrigação penosa de trabalhar — a terceira função no organismo social.

Ou seja, tem-se, a sua maneira, o reconhecimento do trabalho como uma função social, ainda que sejam os trabalhadores em si desprezados, submissos à força terrena, como também fadados a esta posição social pela vontade de Deus. Os "trabalhadores" ofereciam "esse sofrimento em troca da salvação da alma (oferecida pelo clero) e da segurança dos corpos (oferecida pela nobreza]). Justificando-se. Mas também justificando o modo de produção senhorial" (DUBY, 1994, p. 181).

Estas foram as bases teóricas de um sistema que perduraria por séculos, ainda que o trabalho tenha progressivamente ganhado destaque na economia feudal com o declínio da "economia de pilhagem"; ou seja, temse esta evolução da teoria da ordem social eclesiástica inserida umbilicalmente no contexto daquilo que se entende por Revolução Feudal, tanto em suas causas, como em suas consequências. Por fim, vale a ressalva de que tal regime "classificatório" e configurador da vida não era, nem seria possível sê-lo, universal, variando de local a local. Portanto, é possível encontrar neste período camponeses livres, alheios de alguma forma aos referidos jogos 
de poder, e donos de terras habitualmente denominadas como alódios (FRANCO JÚNIOR, 2001).

Entretanto, esta ideologia eclesiástica não se manteve viva por muitos séculos por força exclusiva da Igreja; tendo sido fundamental o papel dos letrados (juristas) na legitimação da "sociedade estamental", para usar um termo clássico da historiografia francesa. Afinal, religião e direito possuíam relação umbilical, tanto o é que o rei era tido como fonte de justiça, com dever de propiciar boa ventura aos povos, a partir da ideia de que a justiça provém de Deus. Portanto, não é difícil perceber o importante papel do direito no que toca à maturação da referida ideologia, normatizada, por exemplo, no texto das Siete Partidas (HESPANHA, 2010).

Com estes breves esclarecimentos, é possível adentrar ao caso das instituições portuguesas.

\section{PORTUGAL}

A história portuguesa se inicia nos idos da referida baixa idade média, período em que já se promovia a revolução feudal pelas mais diversas localidades da Europa. Portanto, surge em um período de grande crescimento demográfico e expansão da produção agrícola, promovendo o renascimento de um comércio pujante. É também um período marcado por "guerras santas" (EFFGEN, 2010), que ocorreram principalmente com os movimentos das Cruzadas e da Reconquista da península ibérica pelos cristãos, ainda que o quadro político não colocasse cristãos e muçulmanos sempre em oposição, haja vista um complexo jogo de poder e alianças (CHEJNE, 1993). Ainda, o período é marcado por conflitos e transformações nas relações entre as ordens sociais e as instituições políticas por toda a Europa, a se abrir portas às estruturas políticas e econômicas que viriam a despontar nos séculos XV, XVI e seguintes.

A península ibérica experimentou evolução razoavelmente singular no contexto europeu, inclusive quanto à fragmentação política presente em toda a Europa. Diversos eram os reinos, cristãos e árabes, que se multiplicavam e sucediam; inúmeros os povos estabelecidos. Tanto que, ao comentar a composição de Portugal, Pinheiro Chagas diz que "a água eram os lusitanos, os romanos foram o sal, e os visigodos a carne, e de tudo isso saiu uma coisa nova, um povo novo, este caldo que depois veio a chamar-se português" (1880, p. 31).

Esta é uma excelente metáfora, haja vista que formação portuguesa foi preenchida com permanências de culturas que se entrelaçavam, umas influenciando as outras, convivendo e, paulatinamente, formando uma nova cultura. Este é um processo encontrado em toda a península ibérica, que, aos poucos, também foi absorvendo elementos da cultura muçulmana (MENDONÇA 2006), seja diretamente ou com os moçárabes, de acordo com as conquistas territoriais rumo ao sul da península (MATTOSO,2000), expandindo os territórios que até o início da baixa idade média se limitavam ao extremo norte da península (COSTA, 2010).

Costuma-se tomar como início da saga portuguesa o ano de 1095, em que o Rei Afonso VI de Leão e vol.11, n. 04, Rio de Janeiro, 2018.pp. 2603-2631 
Castela concedeu ao franco Henrique de Borgonha o condado de Portucale, que consistia nas terras desde o rio Minho até o Rio Mondego (PINHEIRO CHAGAS, 1880). Esta é uma transação típica do período: a concessão a nobres -- e clérigos -- de terras reconquistadas, com ampla autonomia política, sob o manto de vassalagem/senhorio. Com a morte do conde, D. Afonso Henriques veio a governar e expandir o condado por meio de sucessivas vitórias militares (PINHEIRO CHAGAS, 1880).

Neste contexto de sucesso em batalhas D. Afonso Henriques foi aclamado pelas tropas Rei das terras de Portugal (HERCULANO, 1864), que se desmembraram do Reino de Leão logo após a Batalha de Ourique (1139).

A se afastar dos pormenores que envolvem a história de sua fundação, que ainda geram debates, é possível focar nas relações de poder no Portugal medieval e suas transformações no processo de formação nacional. Para isto, passa-se à análise do que se entende neste trabalho como instituição central do Portugal medieval, o rei.

\section{O Rei}

Ao analisar as instituições, é notório o destaque do rei, ainda que não detivesse todas as atenções do período moderno, quando o processo de centralização de poder veio a, em maior medida, concretizar-se.

Como mencionado, à emancipação política se seguiu uma organização política monárquica, em que se consolidaram elementos herdados dos lusitanos, romanos e visigodos, aos quais elementos muçulmanos se juntariam ao longo dos séculos seguintes.

A opção pela monarquia, pode-se dizer, adveio da influência do sistema institucional dos visigodos (BARROS, 1885), que em sua edificação foi inspirada nas "Escrituras, na patrística e em alguns ecos dos textos romanos" (HESPANHA, 1982, p. 302). Entretanto, deixou-se de fora o instrumento de eleições, um relevante instrumento presente cultura política visigótica (BATISTA, 2002), ao optar-se pelo princípio da hereditariedade aristocrática (OLIVEIRA MARTINS, 1880).

Isto não se deu aleatoriamente, pois a pessoa do rei tinha de ter algo superior em relação aos demais nobres: o rei era divino e a mística tem um papel central em sua legitimação. O misticismo, ao contrário do que pode parecer, envolvia todos os graus da sociedade, de ignorantes a letrados; de comuns do povo, passando por nobres e clérigos, ao próprio monarca; afinal, à mística real ninguém se podia furtar, pois seria não acreditar nos augúrios de sucesso do ascendente poder; seria não ter fé no próprio Dominus Deus, ${ }^{3}$ como predeterminava a

\footnotetext{
${ }^{3}$ Cabe a ressalva de que também monarquias por eleição também se legitimavam por meio de mitos; o próprio "processo eleitoral" pode ser encarado como um ritual.
} 
herança cristã visigótica (ANDRADE FILHO, 2013).

Esta mística, naturalmente, conduziu o imaginário político-cultural quanto à própria fundação de Portugal, tendo sido propagada a lenda de que Cristo aparecera antes da Batalha de Ourique a D. Afonso Henriques com a promessa da vitória e sua sagração como rei (PINHEIRO CHAGAS, 1880; RECREIO, 1884), mito que perdurou durante séculos na historiografia (SALGADO, 2010).

Este processo não se restringe a Portugal. Destacam-se os casos de Constantino, cujas vitórias bélicas estavam diretamente atreladas a batismo cristão, a sua submissão ao divino (LAMELAS, 2013); e Clóvis, primeiro chefe político cristão do ocidente, considerado, por inúmeros, fundador da França, um rei "tipicamente francês" (SILVA, 2003, p. 77), promovendo o cristianismo na Europa sete séculos antes de D. Afonso Henriques. Em síntese: a vinculação de um poder político a origens míticas é uma constante na história da realeza, mas também a nobreza e as cidades se utilizaram deste programa (LE GOFF, 1983).

Após o evento fundante de Portugal, destaca-se a eleição do rei D. João I nas Cortes de 1385 contrariando a sucessão hereditária em favor de um processo eleitoral litúrgico para forjar sua dinastia (CRUZ COELHO, 2010), que concomitantemente se utilizou da historiografia como ferramenta para assegurar sua legitimidade e promover as origens divinas de seu poder.

Com isto, deu-se uma radical politização da historiografia, cujos agentes atuaram como construtores de mitos (MATTOSO, 1992). Antes história desinteressada; sob a dinastia de Avis, história oficial, elaborada por um cronista-mor (FRANÇA, 2001) com grande proximidade à pessoa do rei; testemunha ocular dos "fatos", contemporâneo aos acontecimentos (SERRÃO, 1972). ${ }^{4}$

Porém, não apenas de mitos viveram os reis portugueses nos primeiros reinados; estes eram elementos legitimadores iniciais de sua situação de rei, sendo sua função primordial a atividade militar, quando, enfim, rei e reinados estabeleciam contato concreto. Afinal, o rei era em tempos de paz apenas um "vigilante longínquo, quase ideal, de quem os mais velhos diziam [...]. Essa situação manteve-se durante toda a Idade Média e grande parte da Idade Moderna" (MATTOSO, 1998, pp.9-10).

Em estado de guerra, seu papel era de chefe supremo em armas, devendo ser agente ativo nas batalhas, como qualquer guerreiro (MARTINS, 2010); concentrando as tropas a seu redor. Este papel militar é conjuntural: a economia de pilhagem e a reconquista ibérica como duas faces de uma mesma moeda, a "moeda real".

O crescimento do reino e o desenvolvimento econômico-social promoveu a propulsão da instituição

\footnotetext{
${ }^{4}$ Destaque para a relação entre Fernão Lopes e D. João I: “D. João I foi o maior exemplo do "Estado de Rey" que Portugal poderia ter tido em sua história; mais do que um poder transmitido por Deus, o Mestre de Avis e posteriormente, D. João I era a representação personificada do filho de Deus em Portugal” (VIEIRA, 2010, p. 87).
} 
real em meio ao emaranhado jogo político em que atuavam diversos atores, sejam eles nobres, clérigos — locais ou romanos -- comerciantes, outros reis etc.

Entretanto, esta importância deve ser compreendida em um mundo medieval de natureza organicista, como exposto, em que se afasta o pensamento individualista (da imagem centrada no indivíduo, na irredutibilidade de sua natureza ontológica e seus fins). É o que Hespanha denomina teoria corporativa da sociedade (1994); em linguagem popular: "cada um em seu quadrado".

E qual a função deste rei?

Intermediar; conciliar, afinal é um "rei contratual" (LE GOFF, 1999); um "feitor de justiça" (HESPANHA, 1994).

E por meio de que instrumentos era ao rei possível sê-lo?

Ao longo da baixa idade média estes instrumentos se desenvolveram, em especial se ampliando frente a outras instituições, sendo possível mencionar o poder de legislar e administrar a justiça, bem como de cunhar moedas e exercer o padroado sobre instituições religiosas.

Ou seja, a figura do rei, nos primeiros reinados, não se aproximava de um todo poderoso centro de poder; por contrário, devia garantir autonomia política e jurídica aos súditos (CARVALHO HOMEM; CARVALHO HOMEM, 2006; GROSSI, 2007), com base na referida cooperação fundada no corpus orgânico.

Entretanto, com o avanço intelectual e a crescente influência do direito romano de viés dogmático, se desenvolvera a teoria permissionista em favor de um rei como centro do poder delegatário, em oposição à concepção orgânica, cósmica, da ordem de direito natural. Nesta construção o rei se torna figura central, primordial — "monopolizadora" —, que permite, concede, por sua benevolência, o exercício de poder, em especial a jurisdição (HESPANHA, 1982).

Ou seja, aquele que concede pode retirar; aquele que recebe está constantemente submetido ao arbítrio e boa vontade daquele que oferece: eis a fundamentação jurídica para o processo de centralização por que Portugal viria a passar a partir do séc. XIII, com maior peso após o séc. XV.

Enquanto esta doutrina jurídica era desenvolvida, ainda que a prática destas concessões régias visasse a "viabilizar" um direito local autônomo, tais concessões eram muito mais do que uma bondade; eram imprescindíveis à própria manutenção do poder real; eram concessões inevitáveis (HESPANHA, 1982). Os reis — repita-se — dividiam para reinar.

Este quadro, porém, não impediu o avanço das pretensões da coroa, com destaque para a instrumentalização do poder de jurisdição com o objetivo de promover importantes ingerências do poder central nas esferas locais. Este expediente se destacou principalmente no reinado (1211-1223) de D. Afonso II, o "Rei 
Legislador" (DUARTE, 2005), ${ }^{5}$ sendo por isto apontado por Mattoso como o verdadeiro fundador de um Estado português (2000).

Dentre suas medidas, citam-se a normatização de questões na relação com a Igreja; a regulamentação de garantias a vilãos; e um vetor publicizador da jurisdição (HESPANHA, 1982), em especial quanto a um elemento chave à centralização política e ao controle social: a justiça criminal. Destacam-se a regulamentação do delito de traição e de elementos processuais e executórios, como modus e prazo de sanções corporais (SILVA, 1971).

Entretanto, apesar de medidas como estas, reinar seria sempre dividir. Logo não surpreende que a mais notável regulação do período seja, justamente, o reconhecimento da vigência do direito canônico, fortalecendo o pluralismo jurídico do período. Tamanha era força política da Igreja e das ordens religiosas que os tribunais eclesiásticos (foro eclesiástico) prevaleciam em relação ao Tribunal da Corte $^{6}$ e ao direito real (HESPANHA, 1982).

Nitidamente, tal decisão de caráter político alcançou o sucesso desejado pelo monarca, a ponto de levar à emissão da bula Manifestis probatum (1212), por qual o Papa Inocêncio III tornava o soberano português protegido e reconhecia-lhe o direito de conquistar terras de infiéis (DUARTE, 2005); afinal a Igreja se via com soberania absoluta, inclusive sobre a constituição de Estados cristãos, que seriam apenas manifestações de um único "Estado de Deus" na Terra (FRANZEN, 2009).

Com isto, evidencia-se a existência de inúmeras fontes de direito e ordens jurídicas, que às vezes se complementavam, mas, preponderantemente se excluíam. Neste cabo de guerra, o papel do rei era buscar a supressão das demais ordens jurídicas e a supremacia do poder real (GROSSI, 2007), centralizando a vida sob a administração e justiça da coroa. ${ }^{7}$

A utilização pelos reis portugueses do direito como instrumento de atração de poder é uma medida vanguardista, "precoce", se comparado aos demais reinos (CARVALHO HOMEM, 1999). Além das medidas já expostas, destacam-se, já no reinado (1279-1325) de D. Dinis I, as famigeradas leis de 1302 -1306, que insistem na origem divina do rei e de seus atos — tidos como dons de Deus —; a consequente inexistência de qualquer intermediação papal; e a absoluta utilidade comum em qualquer atuação do poder real - "finalidades" (CARVALHO HOMEM, 1999). Por sua vez, no reinado (1433-1438) de D. Duarte I, reiterou-se

\footnotetext{
${ }^{5}$ Não se pode olvidar de que até então já se encontravam leis com caráter geral, mas discretas e não muito organizadas.

${ }^{6}$ Tribunal geral, régio, onde se julgava agravos relativos aos "julgamentos de primeiro grau" dos juízes locais, bem como julgava casos de pessoas que possuíam uma espécie de "foro privilegiado", em termos modernos, como nobres, funcionários públicos, notários etc. Em Portugal, tradicionalmente se reservou ao rei a justiça penal em casos mais graves, bem como o julgamento de recursos;

${ }^{7}$ Este processo de centralização cria todo um novo corpo, composto por letrados (tecnocratas delegados que cuidavam da administração fiscal e judiciária do rei), que promovem um desvio da tradicional noção de nobreza, incrementando ainda mais a crise da tradicional teoria trinária das funções.
} 
definitivamente que o rei é o único sábio o suficiente para guiar o povo e proporcionar o bem comum (SANTANA, 2010).

Ainda assim, era imperioso que o poder real concedesse, vejamos!

\section{O Rei e suas concessões}

\section{$\underline{\text { Instrumentos reais e o poder local }}$}

Desde antes da fundação de Portugal, os principais desafios de governo foram a produção de riqueza e a expansão e manutenção de fronteiras, diretamente relacionadas e dependentes de um processo de povoamento e estruturação administrativa (MARQUES, 1995); ou seja, similar ao processo de colonização brasileira (MENDONÇA, 2006).

A necessidade de povoamento e manutenção territorial acarretou o desenvolvimento de instrumentos voltados à concessão de riquezas e poder, como 1) a carta de foro; 2) a carta de couto; e 3) a carta de povoamento.

As cartas de foro dizem respeito a um objeto que pertence ao rei ou a senhores feudais por direito, o que demonstra a descentralização do período (MARQUES, 1998). Sua concessão, em regra outorgando direito de domínio (DIAS, 1996) e/ou oferecendo privilégios de caráter administrativo e fiscal (RIBEIRO DA SILVA, 1989), ocorria com previsões de contrapartidas ou mesmo por pura benevolência, visando ao povoamento de áreas reconquistadas.

Portanto, as cartas de foro acabaram por ser instrumento de criação dos primitivos municípios portugueses (MARQUES, 1993). Estes, por sua vez, possuíam estruturas diversas (CUNHA, 1988; RIBEIRO DA SILVA, 1989) de acordo com o conteúdo da carta de foro outorgada, pois não havia qualquer sistematização ou modelo global de administração pública local (OLIVEIRA MARTINS, 1880).

Com o passar dos anos, seu teor foi se alterando, em especial por conta da gradativa superação de seu escopo inicial -- o povoamento -- privilegiando regras relacionais entre concedente e concessionários, bem como fixando alguns aspectos de direito público local. Entretanto, ainda não há que se pensar em uma centralização, unificação, da administração pública, pois estas cartas respeitam as tradições locais e, justamente por isso, continuaram a variar quanto a conteúdo, apenas reduzindo a termo costumes locais (HESPANHA, 1982; DUARTE, 1999; SABADELL, 2006).

Podem-se citar como elementos comuns em cartas de foro: a) garantias quanto aos bens e inviolabilidade de domicílio (MARQUES, 1988; MORENO, 2005); b) disposições sobre matéria fiscal; d) normas relativas a serviço militar; e) regras para uso de terrenos comuns; f) encargos e privilégios de cavaleiros e 
de peões; g) meios para a conservação da paz na povoação; h) normas para administração da justiça e multas a serem aplicadas a determinados crimes (RIBEIRO DA SILVA, 1989). São verdadeiros códigos isolados de direito público (HERCULANO, 1853), conferindo bastante autonomia administrativa aos poderes locais, em especial quanto a tributos e administração da justiça, que viriam se tornar objeto de disputa com o poder real. Não obstante a diversidade dentre as cartas de foro, há um elemento que parece sempre presente: a constituição de um concelho, órgão público que será detalhado no próximo tópico.

Por sua vez, a carta de couto, em suma, era reservada para doação de terras às igrejas e mosteiros (DIAS, 1996). Estas cartas ultrapassam significativamente os escopos das concessões de forais. Pois no caso das cartas de couto estavam os habitantes isentos da jurisdição real (HESPANHA, 1982); bem como de diversas obrigações econômicas (DIAS, 1996).

A concessão de coutos a ordens religiosas teve impacto positivo na inserção sociopolítica que a religião Católica obteve na história de Portugal. ${ }^{8}$ Grandes poderes ligados à religião foram desenvolvidos, com destaque para os Monges de Cister, a Ordem do Templo e a Ordem de Cristo; também, em menor escala, a Ordem de Avis e a Ordem de Santiago e, ainda, a Ordem dos Hospitalários (MENDONÇA, 2006), sendo fundamental o papel do clero nas guerras de reconquista (OLIVEIRA MARTINS, 1882).

Por fim, brevemente, as cartas de povoamento se preocupam mais especificamente com o que o nome expressa: povoar os territórios, ocupar os espaços vazios, com pessoas dispostas a trabalhar e transformar estas regiões, indicadas nominalmente e formando grupos de povoadores (MARQUES, 1995). Pode-se entender que a carta de povoamento exprimia um estágio anterior à carta de foro (HESPANHA, 1982), afinal não concedia tamanha autonomia administrativa, fiscal e jurisdicional, sendo viável eventual elevação das vilas de povoamento por meio de cartas forais.

Enfim, resta evidente a importância do direito local em Portugal no período estudado, de modo que se percebe uma enorme fragmentação de poder. Se poderes locais obtinham a manutenção de seus costumes, concessionários de coutos eram verdadeiramente quase monarcas em seus senhorios (OLIVEIRA MARTINS, 1880). Justamente por isso se tem defendido, com destaque para Hespanha, que até hoje se subestima o papel do direito consuetudinário local frente ao poder real, inclusive no período moderno (2005).

\footnotetext{
8 "Afonso Henriques, entre 1128 e 1185 [...concedeu] 167 cartas de couto, outorgadas a prelados diocesianos e respectivas Sés, a Ordens Monásticas e Ordens Religiosas Militares, a diversas igrejas e outras instituições, que deveriam proceder à sua exploração, de acordo com as potencialidades e aptidões naturais" (MARQUES, 1998, p. 525).
} 


\section{Os Concelhos}

Como exposto, as cartas forais possuíam em regra um elemento comum: a formação de um concelho, instituição que representava, simbolizava, o poder local. Sua importância se evidencia pelo fato de que precedeu a fundação de Portugal; sobreviveu à idade média, ao dito "absolutismo"; e até hoje se faz presente (COSTA, 2010), ressalvada a diversidade de características ao longo do tempo, em especial sua natureza interna, bem como sua relação com as demais esferas de poder.

Antes de prosseguir, porém, é imperioso um esclarecimento: este tópico traz os concelhos, apesar de sua já vista pluralidade orgânica, como uma classe, modalidade, de instituição do Portugal medieval, opção didática também utilizada em diversos conceituados trabalhos.

Como exposto, inexistia linearidade na criação e estruturação dos concelhos. Isto porque suas composições e atribuições estavam reguladas por um documento único, ocasional; ainda, não há que se falar em uma estanque cronologia dos concelhos, de modo que eram criados e extintos casualmente, à mercê dos jogos políticos de poder.

O que se pode afirmar quanto a sua evolução é que com o decorrer dos anos passaram por um processo de progressiva redução de autonomia, haja vista o elevado grau de expansão territorial e estabelecimento de fronteiras alcançado pelo país, reduzindo a necessidade real quanto a estes poderes locais (MENDONÇA, 2006).

Os concelhos eram formados por homens denominados "vizinhos", ou seja, homens livres e "bons": pessoas maiores de idade que habitavam a área concelhia havia determinado tempo e que nela trabalhavam ou eram proprietários; eram as elites (TRINDADE, 2012), enquanto os demais, a maioria da população civil, eram os denominados "peões": pequenos proprietários, rendeiros, assalariados, etc (HESPANHA, 1982).

Portanto, vê-se que nobres e clérigos não estavam dentre os integrantes do concelho, pois não se submetiam às leis comuns (leis locais); também mulheres, dependentes de pais ou maridos, estavam afastadas da condição de "vizinhos", bem como indivíduos infiéis, isto é, judeus e mouros. E, por fim, pela própria natureza do concelho, estrangeiros, servos e escravos estavam também alijados da referida posição de destaque.

Quanto a sua estrutura, destacava-se a assembleia como principal órgão deliberativo, que elegia magistrados, criava leis (posturas) e organizava forças militares, pois a função militar não mais era atributo exclusivo de nobres, haja vista a crise do sistema corporativo trinário. A superação deste sistema chegou, inclusive, a fazer com que alguns concelhos tivessem como principal objetivo não o povoamento e a propulsão econômica, mas, sim, a defesa militar do reino, até mesmo com a utilização de fortalezas nas fronteiras (MORENO, 1984; 1993).

Vê-se, portanto, que em regra as funções do concelho lhe conferiam significativo grau de autonomia, a 
ponto de Oliveira Martins falar em "repúblicas concelhias" (1880). Além de bandeiras e emblemas, outros dois elementos são símbolos desta autonomia: o selo "municipal" e o pelourinho. O primeiro, relacionado a autenticações de documentos e, portanto, à criação e estabelecimento de direitos e obrigações; o segundo, a representação da autonomia da administração da justiça, destinado à execução de sanções em ambiente público (CRUZ COELHO, 1997).

\section{$\underline{\text { O Rei e suas vedações }}$}

Como exposto, o poder real viria a obter um incremento progressivo ao longo da baixa idade média. A conjuntura que propiciou este avanço do rei frente a seus oponentes é bastante complexa, em que se fortalecem instrumentos diretos do rei; bem como condições sociais e econômicas gerais, como a existência de um comércio revitalizado, com cada vez mais circulação de moeda e pessoas, o povoamento da costa rumo às navegações; uma emergente burguesia e a paulatina sobreposição econômica da cidade sobre o campo (CRUZ COELHO, 1995).

Sem dúvida, este quadro econômico-social promoveu a virada política real, por meio de ações centralizadoras (HESPANHA, 1982), como a drástica redução de concessões de cartas de privilégio. O poder cada vez mais centralizado visa a superar sua limitação de intervenção decorrente de excessivas -- mas antes necessárias -- concessões de foros, coutos e honras (BARROS, 1885; MARQUES, 1995), aproveitando-se também das fissuras internas na nobreza e no clero (CRUZ COELHO, 1995; BARROCA, 1998).

Destacam-se os movimentos centralizadores dos reinados de D. Afonso II (1211-1223), D. Sancho II (1223-1247), D. Afonso III (1248-1279), D. Dinis (1279-1325) e, com grande eficácia, D. Afonso IV (13251357), quando os concelhos e os senhorios começaram a perder força de modo incontornável (MARQUES, 1995); todos estes reinados tiveram nas Inquirições um poderoso instrumento político, que consubstancia o referido reposicionamento do rei no intricado tabuleiro de poder em que se encontrava.

As Inquirições visavam a dar conhecimento à realeza quanto aos territórios em que de fato exercia poder, bem como domínios reservados aos eclesiásticos e nobres, cuja influência real em regra se limitaria a determinadas cobranças tributárias (MARQUES, 2006). Além disto, buscavam retomar territórios usurpados e devassar jurisdições, em especial aquelas de natureza criminal, ao longo, principalmente, do reinado de D. Afonso IV (MARQUES; CUNHA, 2002). Ou seja, foi possível ao monarca enfraquecer econômica e socialmente tanto nobres como eclesiásticos (SOTTOMAYOR-PIZARRO, 2013).

O governo de D. Afonso IV se conduziu primordialmente com ideia de que seu poder advinha diretamente de Deus, sem intermediários, de modo que seria função principal do rei encaminhar e guiar o povo no caminho da vida (CRUZ COELHO, 1995). Apesar do apoio que dos nobres recebera em sua coroação, 
decidiu enfrentá-los, além dos embates contra os representantes da Igreja. Promoveu uma reforma de grande importância na justiça, com destaque para a determinação de que os fidalgos abdicassem da vindicta em favor de sua submissão à jurisdição real, ou seja, a lhes derrogar um tradicional privilégio de classe (CRUZ COELHO, 1995); bem como promoveu um sistema público de controle de condutas, objetivo de diversos reis medievais (TOMÁS Y VALIENTE, 1969). Por fim, pode-se citar a reestruturação administrativa do reino, de modo que não apenas nobres e clérigos tiveram seu círculo de poder reduzido, mas também os concelhos.

Era nítido que o modelo de administração dos concelhos tendia às centralizações locais de poder em função da propulsão econômica do comércio, que gerava indivíduos cada vez mais fortes e influentes política e economicamente (MORENO, 1994); e o desenvolvimento de figuras individuais tão poderosas não se coadunava com as novas políticas régias, ou seja, as relações de poder entre os reinados deviam ser equilibradas.

O referido trabalho de revisão e fiscalização dos forais, as Inquirições, desenvolveu-se a ponto de a autonomia dos concelhos restar extremamente fragilizada no reinado de D. Afonso IV. Esta interferência se deu sobremaneira por meio dos regimentos de 1332 e 1340, conferindo a corregedores nomeados pelo rei as funções de inspecionar a justiça e a atuação dos magistrados, em especial quando os casos envolviam poderosos locais (MORENO, 1995); bem como a de supervisar a eleição de oficiais e acompanhar a contabilidade pública. Alguns anos depois, foram impostos os famigerados "juízes de fora" sob o argumento de que possuiriam melhor condição técnica e maior imparcialidade na condução da justiça (CRUZ COELHO, 1995), tendo servido durante séculos como instrumento de enfraquecimento das estruturas locais (HESPANHA, 1994).

Portanto, é inegável a importância dos corregedores para o reino (para o rei), tanto que em inúmeras oportunidades viria a ser objeto de legislações, como em 1413, com o infante D. Duarte (SOUSA, 2012), bem como em 1611 e 1640, com Felipe II e Felipe III, quando obtêm um papel ainda mais ativo na condução dos processos e nos procedimentos eleitorais por pelouros (CAPELA, 2009).

Ainda que sejam notórios os problemas de uma centralização da justiça e do controle administrativo, não é possível obliterar um senso de justiça e equidade, ao menos nas motivações expressas, nas funções exercidas pelo corregedor da coroa. Isto estava em absoluta consonância com a cultura política de um monarca bom, justo, divino, pacificador, sábio, porém ainda assim esbarrava em dificuldades logísticas e culturais inerentes ao período relativas ao acesso do rei aos cidadãos do reino e a exequibilidade das normas.

\section{Cortes: os encontros de poderes}

Analisada a esfera de poder local, bem como algumas transformações por que passou, resta possível a 
análise das cortes, ${ }^{9}$ instituição tida como "elemento tradicional" da história peninsular (OLIVEIRA MARTINS, 1880). Sua origem estaria, como a própria monarquia, relacionada a tradições visigóticas (BATISTA, 2002). Explica José Manuel Cerda que:

la curia regia sufrió un proceso de bifurcación y especialización, por el cual el monarca comenzó a reunir a su consejo de forma ordinária, con la presencia de quienes se encontrabam más cercanos al ámbito político de la corona, y de forma extraordinária, convocando a los magnates y a los nobles más importantes del reino. la curia ordinarista tomaría las riendas de la administración ejecutiva del reino y se transformaría, con el tiempo, en la instituición que hoy conocemos como el consejo real, mientras que la reunión plena tomaría decisiones en el ámbito legislativo, fiscal y judicial, con repercusión general para todo el reino (2004:Online).

Por sua natureza, as reuniões das cortes - e daqui em diante tomaremos por cortes aquelas reuniões extraordinárias - sempre foram públicas, podendo os indivíduos presenciá-las livremente (OLIVEIRA MARTINS, 1880). Porém, viriam a englobar outros indivíduos, além de nobres e clérigos, como agentes ativos ao longo da baixa idade média. No Reino de Leão, já em 1188, os concelhos obtiveram assento nas cortes (OLIVEIRA MARTINS, 1880), o mesmo acontecendo em Castela também no séc. XII (O’CALLAGHAN, 1989). Em Portugal, deu-se apenas em 1254, com D. Afonso III, nas Côrtes de Leiria (PINHEIRO CHAGAS, 1880), ou seja, quando já se havia iniciado o processo de enfraquecimento da autonomia dos concelhos, como visto.

O papel dos representantes dos concelhos nestas assembleias é bastante significativo: estar ao lado do rei no combate à nobreza e ao clero para, juntos, enfraquecê-los (PINHEIRO CHAGAS, 1880). Faz lembrar, vagamente, determinadas relações em povos antigos. Ainda que não se possam comparar as referidas relações sociais, inseridas em contextos tão diversos, nota-se similaridade: a união entre uma instituição — rei/tirano —, que almeja concentrar o máximo de poder, e o concelho/povo, que se sente isolado na sociedade política e oprimido pelo inimigo comum — a nobreza —, verdadeiro empecilho à consecução de objetivos específicos dos integrantes da união (COULANGES, 1975, original de 1864).

Porém, não se tratam de "três estados", como defendeu Oliveira Martins (1880). Conforme apontou Pinheiro Chagas, inexistem estratificações sociopolíticas tão rígidas no período (1880). Não havia sentimentos comuns seja dentre nobres, clérigos ou procuradores de concelhos; estavam todos enfraquecidos perante o rei (BARROS, 1885). Em segundo lugar, lembra-se a mencionada elitização dos concelhos, que não se mostram como representações populares sob o conceito de "povo" dos anos de Oliveira Martins (1845-1894), afinal estava alijado de representação concelhia. Seus procuradores nas cortes não representavam a "vontade do povo", mas, a vontade de elites locais (MARQUES, 1987).

\footnotetext{
9 "Corte (de cohoros, cohostis, pátio, e daí, lugat de reunião) é a denominação vulgar dada à "Cúria Régia, que se amplia para a Cúria Plena" (AZEVEDO, 1995, p. 72).
} 
Apontadas a origem e a composição das cortes, pergunta-se: quais eram suas funções e sua relação com a figura real? Comecemos pela segunda.

Em primeiro lugar, possuía o rei a exclusiva prerrogativa de convocá-las (OLIVEIRA MARTINS, 1880), não seguindo qualquer periodicidade, afinal o programa político do rei e as circunstâncias determinavam sua necessidade. A título de exemplo, Afonso X de Castela, concedendo amplo espaço a este órgão, convocou-o vinte e cinco vezes ao longo dos trinta e dois anos de seu reinado (1252-1284) (JIMÉNEZ, 2004). Segundo Armindo de Sousa, em Portugal as cortes teriam se reunido ao menos setenta e seis vezes entre os anos de 1254 e 1495 (1990); entretanto, seria apenas no século XV que as cortes encontrariam seu apogeu (NASCIMENTO, 2010).

Seguindo suas origens visigóticas (OLIVEIRA MARTINS, 1880), as cortes realizavam pareceres quanto às questões levadas pelo monarca a sua consulta, sendo indiscutível a importância dos representantes daqueles "grupos sociais" na tomada de decisões do reino.

Além disso, ao rei eram levadas súplicas relativas aos mais diversos assuntos, em regra de caráter particular, local. Aos poucos as súplicas passaram a ser "mais bem protestos e ameaças, quando não chegavam a ser positivas affirmações de soberania" (OLIVEIRA MARTINS, 1880, p. 155), longe de ser entendida pela acepção atual (conteudista), afinal o único soberano (absoluto, ilimitado) no período medieval seria Deus (GROSSI, 2014).

Portanto, é clara a importância, o poder e a influência das cortes nos negócios do reino em diversos âmbitos da vida pública, em contrapartida à queda de autonomia das instituições locais.

A título de exemplo, destaca-se a eleição de D. João, então Mestre de Avis, à coroa. Nas palavras de Pinheiro Chagas, "reuniram-se cortes em Coimbra, para se escolher um rei. Ai teve D. João I outro amigo, advogado de mão cheia, fino como um coral, chamado João das Regras, que foi quem the fez ganhar a eleição" (1880, p. 77); inclusive, traz que, por ventura da escassa representação dos nobres às cortes,$^{10}$ os procuradores dos concelhos ${ }^{11}$ tiveram decisiva participação na aclamação do Mestre de Avis, com o objetivo de impedir um reinado estrangeiro. Talvez nestas cortes se tenha experimentado algo próximo do sentimento nacional característico dos séculos XV e seguintes (OLIVEIRA MARTINS, 1882).

Enfim, alheio às relevantes discussões quanto à origem dos parlamentos modernos nas cortes, ${ }^{12} \mathrm{o}$ que demandaria uma profunda construção acerca do próprio parlamento moderno, pode-se afirmar que as cortes foram fundamentais à formação de Portugal. Certamente, proporcionaram aos portugueses uma cultura de proximidade política entre monarcas e súditos — ainda que sem universalidade — em uma relação de mútuo

\footnotetext{
${ }^{10}$ Este é famoso período do Interregno (1383-1385), em que se debateu quem seria o próximo rei, tendo diversos nobres de Portugal se aliado a Castela em uma ofensiva militar contra a posição portuguesa.

${ }^{11}$ Fernão Lopes traz que estavam presentes nesta Côrte "cincoenta procuradores de villas e cidades do reino" (1897, p. 175).
} 
respeito; não à toa Gama Barros escreveu que a reunião em cortes, apesar da inconstância, era uma tradicional obrigação que se impunha aos reis (1885).

Por todo o exposto, nota-se que as cortes promoveram a cultura do rei como "senhor dos senhores", nos termos de D. João II em Cortes de Évora (já em 1481) (SOUSA, 1989), o que não significa outra coisa senão uma superioridade do poder real acordada, negociada, ainda que de forma desigual. E acordos preveem obrigações mútuas entre "partes"; não, "todos absolutos".

\section{CONCLUSÕES}

Buscou-se ao longo do trabalho o máximo cuidado com contextualização, evitando simplificações e, quando inevitáveis, alertar acerca de sua presença, pois nos parece que esta metodologia é imprescindível à percepção do quadro político-institucional do objeto: no caso, o Portugal medieval.

E o que se percebe nesta realidade?

Um país em formação, a forjadura de uma nação e sua cultura em meio a embates políticos na luta por poder. Um reino que em alguns períodos vê a transformação de um chefe militar em um intermediador e guardião do poder das instituições, que em seguida ruma a se tornar o pastor de toda a vida terrena e das próprias instituições cuja autonomia antes protegia; eis que a figura do rei medieval se torna a de um "rei Real".

A história dos concelhos e das cortes demonstra o caráter plural do período; são a representação de algum grau de tolerância e concorrência político-jurídica; mais do que isso, demonstram a relação umbilical entre força e direito. É um período de plena luta pelo “direito", em que as instituições se transformam durante o tempo de acordo com o sucesso ou o fracasso de seu processo de absorção e perda de poder.

Em meio a este complexo quadro em que desponta progressivamente o poder real, afirma-se a existência de um pluralismo político e jurídico institucionalizado - que nos parecem dois significantes para um mesmo significado. E esta pluralidade está distante dos dogmas monistas que orientam as estruturas de poder atualmente; fala-se na existência de uma "constelação de ordens normativas" (HESPANHA, 2005:163-6) no céu medieval, podendo servir de base para novos debates e possibilidades nos processos políticos contemporâneos.

\footnotetext{
${ }^{12}$ Destaca-se Armindo de Sousa na defesa de um verdadeiro "Parlamento Português" no período medieval (1990).
} 


\title{
POLITICAL AUTHORITY, INSTITUTIONS, AND LEGAL PLURALISM IN MEDIEVAL PORTUGAL
}

\begin{abstract}
The present work aims to discuss institutional conflicts in the midst of a historical experience of legal pluralism, looking to depict an example of dispute for institutional political power in which the main instrument is the jurisdictional expansion. To accomplish that, classic Portuguese historiography is studied under the current rules of historiographical methodology, to which is added the scrutiny of the more recent bibliography that has resumed the debate about the affairs between local and central political institutions in medieval Portugal, and the exercise of their jurisdiction. Based on the results obtained, it is possible to acknowledge the importance of historical examples in debates about political institutions and their affairs, as well as the role of jurisdiction as an essential instrument of amassment of power since the foundations of our political culture.
\end{abstract}

Keywords: institutional conflicts; legal pluralism; central and local political power; political history; history of Portugal.

\section{REFERÊNCIAS BIBLIOGRÁFICAS}

ALMEIDA COSTA, M.J. História do Direito Português. 4a ed. rev. e amp. Coimbra [Portugal]: Almedina, 2010.

ANDRADE FILHO, R. Mito e monarquia na Hispânia visigótica católica. Temas Mediev., Buenos Aires, v. 13, nº 1, 2013. Disponível em: http://www.scielo.org.ar/scielo.php?script=sci_arttext\&pid=S032750942005000100002. Acesso em 14 de fevereiro de 2018.

AZEVEDO, L. C. Ainda a origem e introdução da apelação no direito lusitano. Revista da Faculdade de Direito da Universidade de São Paulo, São Paulo, v. 90, pp. 67-82, 1995.

BARROCA, M. J. D. Dinis e a arquitectura militar portuguesa. Revista da Faculdade de Letras: História, Porto [Portugal], série II, v. 15-I, pp. 801-822, 1998. 
BARROS, H. da Gama. Historia da administração pública em Portugal. 5 TOMOS: Tomo I, Lisboa: Imprensa Nacional, 1885.

BATISTA, N. Matrizes ibéricas do sistema penal brasileiro. 2a ed. Rio de Janeiro: Revan; ICC, 2002.

BLOCH, M. A sociedade feudal. Trad. Emanuel Lourenço Godinho. Lisboa: Edições 70; São Paulo: Martins Fontes, 1992.

CAPELA.J.V Eleições e sistemas eleitorais nos municípios portugueses de antigo regime In: CRUZ, M. A. (Org.). Eleições e sistemas eleitorais: perspectivas históricas e políticas. Porto [Portugal]: Universidade do Porto, 2009, pp. 21-82.

CARVALHO HOMEM, A. L. Rei e <<estado real>> nos textos legislativos da Idade Média. En la España Medieval, Madrid [España], n.o 22, pp. 177-185, 1999.

CARVALHO HOMEM, A. L.; CARVALHO HOMEM, M. M. Lei e poder concelhio: as posturas. O exemplo de Lisboa (sécs. XIV-XV) (primeira abordagem). Revista da Faculdade de Letras: História, Porto [Portugal], série III, v. 7, 2006, pp. 35-50.

CERDA, J. M. La presencia de caballeros y ciudados en la Curia Regia y el origen de las asambleas parlamentarias en Inglaterra y los Reinos Hispánicos (s. XII-XIII). Kíneses: Revista electrónica de metodología e historia del derecho, Madrid [Espanha], v. n. ${ }^{\circ}$ I, 2004.

CHEJNE, A. G. História de España Musulmana, Trad. Pilar Vila. Madrid: Cátedra, 1993.

COELHO DIAS, G.. Na variedade dos Foros, a singularidade dos Coutos Beneditinos Generosidade régia e poder monástico In: Congresso histórico de Guimarães. Sociedade, administração, cultura e igreja em Portugal no séx. XII. 2º. 1996, Guimarães. Actas do Congresso, V 4, Guimarães: Câmara Municipal de Guimarães; Universidade do Minho, 1996.

COULANGES, F. A cidade antiga: estudos sobre o culto, o direito, as instituições da Grécia e de Roma. Trad. Jonas Camargo Leite e Eduardo Fonseca. São Paulo: Hemus, 1975. 
CRUZ COELHO, M. H. Memória e propaganda legitimadora do fundador da monarquia de Avis In: NOGUEIRA, C. (Org.). O Portugal medieval: monarquia e sociedade. São Paulo: Alameda, 2010, pp. 61-79.

CRUZ COELHO, M. H. O poder e a sociedade ao tempo de D. Afonso IV. Revista de História. Porto [Portugal], vol. 13, pp. 35-52, 1995.

CUNHA, M. Cristina. Forais que tiveram por modelo o de Évora de 1166 Revista da Faculdade de Letras: História, Porto [Portugal], Série II, v. V, pp. 69-94, 1988.

DUARTE, L. M. Justiça e criminalidade no Portugal medievo (1459-1481). Lisboa: Fundação Calouste Gulberkian; Fundação para a Ciência e Tecnologia, 1999.

DUARTE, Maria. T. Dom Afonso II e as Cortes portuguesas de 1211: uma proposta de reorganização da vida cotidiana da sociedade Portuguesa. OPSIS - Revista do NIESC, UFG, Catalão [Brasil], v. 5, pp. 137-150, 2005.

DUBY, G. As três ordens ou o imaginário do feudalismo 2a Ed. Trad. Maria Helena Costa Dias. Lisboa: Editorial Estampa, 1994.

EFFGEN. A. R. A imagem do monarca D. Dinis: uma análise comparada entre a Crônica geral de Espanha de 1344 e a Crônica de Portugal de 1419 In: NOGUEIRA, C. (Org.). O Portugal medieval: monarquia e sociedade. São Paulo: Alameda, 2010, pp. 91-98.

FRANÇA, S. Concepções de História dos Primeiros Cronistas Régios Portugueses História. São Paulo, n. 20, pp. $117-134,2001$.

FRANCO JÚNIOR, H. A idade média: nascimento do ocidente. $2^{a}$ ed. rev. e ampl. São Paulo: Brasiliense, 2001. FRANZEN, A. Historia de la Iglesia. Nueva edición rev. Bruno Steimer, amp. Roland Frölich. Santander [Espanha]: Sal Terrae, 2009.

GROSSI, P. A ordem jurídica medieval. Trad. de Denise Rossato Agostinetti; rev. téc. Ricardo Marcelo Fonseca. São Paulo: Editora Martins Fontes, 2014. 
GROSSI, P. Da sociedade de sociedades à insularidade do estado entre medievo e idade moderna. Revista Seqüência, Florianópolis, n. 55, p. 9-28, dez. 2007.

HERCULANO, A. Historia de Portugal (desde o começo da Monarchia até o fim do Reinado de Affonso III). 3 Tomos: Tomo Segundo. $3^{a}$ ed. Lisboa: Bertrand, 1864.

HERCULANO, A. História de Portugal. 2a ed. 3 Tomos: Tomo Primeiro, Lisboa: Bertrand, 1853.

HESPANHA, A. M. A política perdida: ordem e governo antes da modernidade. Curitiba: Juruá, 2010.

HESPANHA, A. M. Às vésperas do Leviathan: instituições e poder político (Portugal — séc. XVII). Coimbra: Livraria Almedina, 1994.

HESPANHA, A. M. História das Instituições. Épocas medieval e moderna. Coimbra [Portugal]: Almedina, 1982.

HESPANHA, A. M. Historiografia jurídica e política do direito (Portugal, 1900-50). Análise Social, Lisboa, v.. XVIII, n. 72-73-74, pp. 795-812, 1982.

HESPANHA, A. M. O direito dos letrados no império português. Florianópolis: Fundação Boiteux, 2006.

HESPANHA, A. M. O historiador e o cidadão: História e ciência política In: HESPANHA, A. M. Caleidoscópio do Antigo Regime. São Paulo: Alameda, 2012, pp. 76-93.

HESPANHA, A. M.. Cultura jurídica européia: síntese de um milênio. Florianópolis: Fundação Boiteux, 2005.

JIMÉNEZ, M. Alfonso X el Sabio, 1252-1284. Barcelona [Espanha]: Ariel, 2004.

LAMELAS, I. Constantino: da história ao mito, do mito à lenda. Itinerarum. Revista Quadrimestral de Cultura, Lisboa, Ano 59, N. . 206, pp. 191-227, 2013.

LE GOFF, J. La civilización del Occidente medieval. Trad. Godofredo González. Barcelona: Paidós, 1999. 
LE GOFF, J. O maravilhoso e o quotidiano no Ocidente Medieval. Liboa: Edições 70, 1983.

LE GOFF.J. As raízes medievais da Europa. Trad. Jaime A. Clasen. Petrópolis: Vozes, 1997.

LOPES, F. Chronica de El-Rei D. João I. 2 Tomos: Tomo Primeiro, Lisboa: Escrptorio, 1897.

MANFRED, A. Z. A grande revolução francesa. 2a ed. Trad. Maria Aparecida de Camargo e Antonia da Costa Simões. São Paulo: Ícone, 1986.

MARQUES, G. Da gesta e da Honra: notas de História Social nas Inquisições à Terra da Maia In: Estudos \& Documentos. Douro [Portugal], n. 21, pp. 241-256, 2006.

MARQUES, J. Nova história de Portugal, Portugal na Crise dos Séculos XIV e XV. Lisboa [Portugal]: Presença, 1987.

MARQUES, J. O Concelho alentejano de Figueira e a Ordem de Avis, em 1336. Revista da Faculdade de Letras: História, Porto [Portugal], n. ${ }^{5}$, pp. 95-112, 1988.

MARQUES, J. Os municípios na estratégia defensiva dionisina. Revista da Faculdade de Letras: História, Porto [Portugal], série II, vol. 15, nº 1, pp 523-44, 1998.

MARQUES, J. Os municípios portugueses dos primórdios da nacionalidade ao fim do reinado de D. Dinis. Revista da Faculdade de Letras: História, Porto [Portugal], Série II, vol. 10, pp. 69-90, 1993.

MARQUES, J. Povoamento e defesa na estruturação do Estado medieval português. Revista de História. Porto [Portugal], v. 13, pp. 9-34, 1995.

MARQUES, J.; CUNHA., M. C. Conflito de jurisdições e documentos judiciais. O caso de Braga In: Congresso Internacional de Diplomática, Set 2002, Bolonha (Itália), p. 8. Disponível em: https://repositorioaberto.up.pt/bitstream/10216/54849/2/cristinacunhaconflitos000122989.pdf. Acesso em 27 de fevereiro de 2018. 
MARTINS, A. D. Fernando, "pela graça de deus rei de Portugal e do algarve": dignidade e ofício In: NOGUEIRA,

C. (Org.). O Portugal medieval: monarquia e sociedade. pp. 101-124. São Paulo: Alameda, 2010.

MATTOSO, J. A formação da nacionalidade. In: TENGARRINHA, J. (Org.) História de Portugal. Bauru: EDUSC; São Paulo: UNESP; Liboa: Instituto Camões, 2000, pp. 7-17.

MATTOSO, J. As três faces de Afonso Henriques. Penélope - fazer e desfazer a história, Lisboa, n. o 8, pp. 25-42, 1992.

MATTOSO, J. O léxico feudal. Penélope - fazer e desfazer a história, Lisboa, n. ${ }^{\circ}$ 1, pp. 11-40, 1988.

MENDONÇA, M. Introdução à história medieval de Portugal. OPSIS - Revista do NIESC, UFG, Catalão [Brasil], v. 6, pp. 142-155, 2006.

MICHELET.J. A Agonia da Idade Média. São Paulo: Edusc, 1992.

MONTESQUIEU, C. de. Do Espírito das Leis. Trad. Helena Barbosa (rev. Bruno Barbosa). São Paulo: Edições Cultura, 2 volumes, v. 2, 1945.

MORENO, H. B. Abusos e violências na região da beira interior durante o reinado de D. Afonso V. Revista de História das Ideias, v. 5, pp. 175-192, 1984.

MORENO, H. B. Dois concelhos medievais da beira interior: Sabugal e Sortelha. Revista de Guimarães, Guimarães [Portugal], n. ${ }^{\circ}$ 103, pp 345-358, 1993.

MORENO, H. B. Os marginais no Portugal medievo. Comportamentos anti-sociais perante as normas de hospitalidade. Revista Lusófona de Ciências Sociais, Lisboa, n. 2, pp. 99-107, 2005.

MORENO, H. B.. A presença dos corregedores nos municípios e os conflitos de competência (1332-1459). Revista de História. Porto [Portugal], vol. 13, pp.77-120 1995.

MORENO, H. B.; DUARTE, L.; AMARAL, L. História da administração portuguesa na idade media. Um 
balanço. Revista de la Sociedade Española de Estudios Medievales, Ediciones de la Universidad de Murcia, Murcia [Espanha], n.o 1, pp. 87-98, 1991.

MORENO. H. B. As oligarquias urbanas e as primeiras burguesias em Portugal. Revista da Faculdade de Letras: História, Porto [Portugal], Série II, vol. 11, pp 111-136, 1994.

NASCIMENTO, R. As cortes portuguesas durante o governo de D. Afonso V (século XV). OPSIS - Revista do NIESC, UFG, Catalão [Brasil], v. 10, n. 2 pp. 101-119, jul-dez 2010.

O' CALLAGHAN, J. F. Las Cortes de Castilla y León, 1188-1350. Valladolid [Espanha]: Âmbito, 1989.

OLIVEIRA MARTINS, J. P. Historia da Civilisação Iberica. 2a ed. amp. Lisboa: Viuva Bertrand, 1880.

OLIVEIRA MARTINS, J. P. História de Portugal. 2 Volumes. Vol. 2, 3a ed. ampl. Lisboa: Viuva Bertrand, 1882.

PINHEIRO CHAGAS, M. História alegre de Portugal. 5a ed. Lisboa: Emprêsa Literária Universal, 1880.

PIRENNE, H. As cidades da Idade Média — Ensaio de uma história econômica e social. 3. ed. Trad. Carlos Montenegro Miguel. Mira-Sintra [Portugal]: Europa-América, 1973.

RECREIO, F. A batalha de Ourique e a História de Portugal de Alexandre Herculano - contraposição e criticohistorica. Lisboa: Tipographia de G. M. Martins, 1884.

RIBEIRO DA SILVA, F.. O foral de Cambra no conjunto dos forais manuelinos. Revista da Faculdade de Letras: História, Porto [Portugal], Série II, vol. 06, pp. 223-238, 1989.

SABADELL, A. L. Tormenta juris permissiones. Tortura e Processo Penal na península Ibérica (séculos XVIXVIII). Rio de Janeiro: Revan, 2006.

SABADELL, Ana Lúcia. Reflexões sobre a Metodologia na História do Direito. Cadernos de Direito, UNIMEP, Piracicaba, v. 2, n $4,2003$. 
SALGADO, R. S. Entre a coroa e a espada: um estudo da figura guerreira de Afonso Henriques a partir da guerra de reconquista. In: NOGUEIRA, C. (Org.). O Portugal medieval: monarquia e sociedade. São Paulo: Alameda, 2010, pp. 55-60.

SANTANA. D. A noção de bem comum e a legitimação do poder (Portugal - século XV). In: NOGUEIRA, C. (Org.). O Portugal medieval: monarquia e sociedade. São Paulo: Alameda, 2010, pp. 143-151.

SANTOS, P. As relações Estado Igreja na documentação eclesiástica: fontes para a compreensão da autoridade episcopal. Revista Eletrônica Documento/Monumento, UFMT-NDIHR, Cuiabá, v. 1, n. 1, pp. 97-108, Dez 2009. SERRÃO, J. A Historiografia Portuguesa. Verbo: Lisboa, 1972.

SILVA, M. A realeza cristã na Alta Idade Média: os fundamentos da autoridade pública no período merovíngio, (séculos V-VIII). São Paulo: Alameda, 2008.

SILVA, N. Livro das Leis e Posturas (leitura paleográfica de Maria Teresa Campos Rodrigues). Lisboa: Universidade de Lisboa; Faculdade de Direito, 1971.

SOTTOMAYOR-PIZARRO, J. A. de. As inquirições medievais portuguesas (séculos XIII-XIV). Fonte para o estudo da nobreza e memória arqueológica - Breves apontamentos. Revista da Faculdade de Letras Ciências e Técnicas do Patrimônio, Porto [Portugal], v. XII, pp. 275-292, 2013.

SOUSA, A. A estratégica política dos municípios no reinado de D. João II. Revista da Faculdade de Letras: História, Porto [Portugal], série II n. ${ }^{\circ}$ 6, pp 137-174, 1989.

SOUSA, A. O parlamento medieval português - perspectivas novas. Revista da Faculdade de Letras: História, Porto [Portugal], série II, vol. 7, pp. 47-58, 1990.

SOUSA, R. O Rei e os concelhos: a relação entre poderes a partir dos capítulos das Cortes de 1436. Plêthos, Niterói, nº 2, vol 1, pp. 197-210, 2012.

TOMÁS Y VALIENTE, F. El derecho penal de la monarquía absoluta (Siglos XVI-XVII-XVIII). Madrid [Espanha]: Tecnos, 1969 
TRINDADE, L. Casas da Câmara ou Paços do Concelho: espaços e poder na cidade tardo-medieval portuguesa In: RIBEIRO, M. C.; SOUSA MELO, A. (Coords.). Evolução da paisagem urbana: sociedade e economia. Braga [Portugal]: CITCEM, 2012, pp. 209-226.

VENTURA, M. G. Os coutos de homiziados nas fronteiras com o direito de asilo. Revista da Faculdade de Letras: História, Porto [Portugal], série II, v. 15, n. 1, pp 601-626, 1998.

VIEIRA. A. Três reis e um cronista: discursos e imagens nas crônicas de Fernão Lopes In: NOGUEIRA, C. (Org.). O Portugal medieval: monarquia e sociedade. São Paulo: Alameda, 2010, pp. 81-90.

Trabalho enviado em 12 de abril de 2018

Aceito em 05 de julho de 2018 